\title{
ADERÊNCIA ÀS NORMAS INTERNACIONAIS DE CONTABILIDADE PELAS EMPRESAS BRASILEIRAS
}

\section{COMPLIANCE WITH INTERNATIONAL STANDARDS ON ACCOUNTING BY BRAZILIAN COMPANIES LISTED}

\author{
Mac Daves de Morais Freire ${ }^{a}$; Michele Rílany Rodrigues Machado ${ }^{b}$; \\ Lúcio Souza Machado ${ }^{c}$; Emerson Santana Souza ${ }^{d}$; Johnny Jorge de Oliveira ${ }^{e}$ \\ ${ }^{a}$ Professor Assistente da Universidade Federal de Goiás \\ Doutorando em Controladoria e Contabilidade pela FEA/USP \\ Goiânia, GO - Brasil; E-mail: macdmfreire@yahoo.com.br \\ ${ }^{b}$ Professora da Universidade Federal de Goiás \\ Mestre em Ciências Contábeis pelo Programa Multiinstitucional e Inter-regional de Pós-graduação da UNB/UFPB/UFRN \\ Goiânia,GO - Brasil;E-mail:michelerilany@gmail.com \\ c Professor do Instituto Aphonsiano de Ensino Superior e da Universidasde Federal de Goiás \\ Mestre em Controladoria e Contabilidade Estrategica pelo Centro Universitário Álvares Penteado - UniFECAP \\ Goiania, GO - Brasil; E-mail: lucio@florestaauditores.com.br \\ ${ }^{2}$ Professor da Universidade Federal de Goiás. \\ Mestre em Ciências Contábeis pelo Programa Multiinstitucional e Inter-regional de Pós-graduação da UNB/UFPB/UFRN \\ Goiania, GO - Brasil; E-mail: emerson.professor@yahoo.com.br \\ e Professor Assistente da Universidade Federal de Goiás (UFG) e \\ Analista em Organização e Finanças da Controladoria Geral do Município da Prefeitura Municipal de Goiânia. \\ Goiânia, GO - Brasil; E-mail: johnnyjorge@hotmail.com
}

\section{Resumo}

No Brasil, o processo de convergência às normas internacionais de contabilidade teve início com as alterações da lei das Sociedades Anônimas (6.404/76), promovidas pelas leis 11.638/07 e 11.941/09. A legislação fiscal brasileira sempre influenciou a prática contábil. Contudo, a nova legislação possibilitou a separação de critérios contábeis e fiscais para a avaliação patrimonial. O presente estudo visa responder a seguinte questão: Será que as empresas, diante de uma situação de alteração da legislação e normatização vigentes, porém com a possibilidade de adotar práticas alternativas, adotariam estas novas práticas, em detrimento das antigas, promovendo uma contabilidade de fato e de direito plenamente idênticas, no tocante aos critérios de depreciação? Para atingir este objetivo, um estudo empírico sobre as empresas brasileiras listadas na BM\&F Bovespa foi realizado. Os resultados indicaram que um percentual elevado de empresas adotaram as novas práticas. No entanto, ainda foram identificadas empresas que utilizam as taxas fiscais para apuração da depreciação de ativos imobilizados.

Palavras-chave: Convergência, depreciação, taxas fiscais de depreciação, taxas por estimativa de vida útil econômica, imobilizado.

\section{Abstract}

In Brazil, the convergence process to international accounting began with the changes of the corporate law (6404/76), fomented by the laws 11638/07 and 11941/09. The Brazilian tax law has always influenced the accounting practice. But the new legislation allowed the complete separation of accounting and tax criteria for asset valuation. The present study aims to answer the following question: In case of changes in the existing legislation and regulation, but with the possibility to adopt alternative practices, would companies follow the new practices instead of the former ones, leading to a fully identical accounting practices and regulations, as for the depreciation criteria? In this regard, we performed an empirical study on Brazilian companies listed in BM\&F Bovespa. The results indicated that a high percentage of companies have adopted new practices. However, companies using tax rates for calculating the depreciation of fixed assets were identified.

Keywords:Convergence, depreciation, depreciation rates, estimated economic lifetime rate, fixed assets.. 


\section{INTRODUÇÃO}

Considerada como a linguagem universal dos negócios, a contabilidade vem passando por um processo de convergência das normas contábeis, por iniciativa de diversos países. $\mathrm{O}$ principal normatizador contábil no mundo é o IASB - International Accounting Standards Board, que emite as IFRS - International Financial Reporting Standards. O objetivo do IASB é "desenvolver, com base em princípios claramente articulados, um conjunto único de pronunciamentos contábeis de alta qualidade, compreensíveis, exequíveis e aceitáveis globalmente" (IFRS, 2011).

Recentemente, o Brasil, por intermédio de legislações específicas, passou a fazer parte desse processo de convergência, através da sanção das leis 11.638/07 e 11.941/09, que alteram em parte a lei 6.404/76 (lei das sociedades anônimas). A nova legislação determinou que a CVM - Comissão de Valores Mobiliários - adotasse a normatização contábil de acordo com os padrões internacionais, permitindo ainda que os reguladores firmassem convênio com a entidade que estudava e produzia tais normas. Esse dispositivo legal permitiu que o CPC Comitê de Pronunciamentos Contábeis, criado em 2005, passasse a ser o principal produtor de normas contábeis no Brasil. O direcionamento do CPC é para a convergência total com as normas produzidas pelo IASB.

Esse processo de convergência vem sendo aplicado gradualmente desde então, tendo o seu ápice para o exercício de 2010, durante o qual as companhias abertas foram obrigadas a adotar as normas internacionais de contabilidade em sua forma completa.

Porém, nem todo processo de harmonização ou convergência é infalível, em face da existência de peculiaridades entre os países participantes deste processo. É importante destacar que o processo de harmonização é distinto do processo de convergência. A harmonização permite a aproximação das normas e práticas entre os países, buscando preservar as particularidades inerentes de cada um, e possibilitando a reconciliação dos sistemas contábeis a fim de melhorar a troca de informações a serem interpretadas e compreendidas (Niyama, 2005). Já a convergência passou a ser bastante utilizada com o intuito de definir a trajetória dos países na adoção integral dos International Accounting Reporting Standards (IFRS (Ikuno et al., 2010).

Diversos autores pesquisaram sobre as diferenças nos padrões e práticas contábeis entre os países. Weffort (2005), além de apontar as principais causas dessas diferenças, afirma ainda que esse processo pode conduzir à existência de uma contabilidade de fato e outra de direito. Corroborando o pensamento de Weffort (2005), Carmo et al. (2011) asseveram que apesar da ressaltada relevância da convergência internacional da contabilidade, a simples introdução das normas, sem considerar os aspectos culturais e institucionais dos países, pode levar a uma adoção de jure (de direito) e não de facto (de fato) das normas, o que prejudicaria o processo de uniformização das práticas contábeis, transformando a convergência em uma simples questão de formalidade. É importante ressaltar que a contabilidade de direito trata da uniformidade da regulação contábil, da convergência entre as normas, enquanto que a contabilidade de fato diz respeito à adoção na prática cotidiana das empresas (Weffort, 2005; Tay e Parker, 1990 in Carmo et al. , 2011).

Kvaal e Nobes (2010) conduziram um estudo sobre as diferenças entre as práticas contábeis atuais de países que já adotaram as normas internacionais de contabilidade, quando as mesmas permitiam avaliações alternativas, principalmente baseadas em práticas locais prénormas internacionais de contabilidade - IFRS. Eles chegaram à conclusão de que, na maioria dos casos em que era possível a avaliação alternativa, a prática adotada era a da norma local. 
No Brasil, a prática contábil sempre teve forte influência de legislações fiscais específicas, que definiam critérios de avaliação e contabilização para diversos itens patrimoniais e de resultado. As taxas de depreciação de bens do ativo imobilizado, amplamente utilizadas pelas empresas, em evidente inobservância dos critérios adequados de depreciação que respeitam o tempo de vida útil econômica dos bens, constitui um claro exemplo desta prática. $\mathrm{O}$ avanço da nova legislação nesse sentido foi salutar, pois permitiu que as empresas passassem a adotar critérios estritamente contábeis em suas avaliações, e que os ajustes necessários ao processo de convergência, não tivessem efeitos tributários, liberando as amarras à qual a contabilidade brasileira estava sujeita. Para controlar os ajustes necessários para a anulação dos efeitos tributários da conversão às normas internacionais de contabilidade, foi criado o RTT - regime transitório de tributação, por força do artigo 15 da Lei 11.941/2009.

Contudo, o questionamento ainda persiste: será que as empresas, diante de uma situação de alteração da legislação e normatização vigentes, porém com possibilidade de adoções de práticas alternativas, adotariam as novas práticas, em detrimento das antigas, promovendo uma contabilidade de fato e de direito plenamente idênticas, no tocante aos critérios de depreciação?

Além dessa introdução, o referencial teórico sobre os principais assuntos que permeiam o tema é analisado a seguir. Ao final, são apresentados os resultados de uma pesquisa empírica sobre empresas brasileiras listadas em bolsa, do setor de Bens Industriais, e suas práticas sobre a adoção de taxas fiscais de depreciação e taxas baseadas na vida útil econômica dos bens do ativo imobilizado.

\section{REFERENCIAL TEÓRICO}

\subsection{Diferenças nos padrões e práticas contábeis entre os países}

Ao considerar a contabilidade como linguagem universal dos negócios, pode-se presumir ainda que essa linguagem seja única e aplicável a qualquer país ou ambiente de negócios, em qualquer situação. Porém, essa não é uma verdade absoluta, pois os padrões e práticas contábeis entre os países diferem, e em muitos casos, substancialmente.

Segundo Ikuno et al. (2010) é notável o crescente número de pesquisas acerca dos fatores que influenciam as diferenças entre padrões e práticas contábeis entre os países, após o período de 1960 a 1965. Dentre estes estudos, citam-se Nobes (1998); Weffort (2005); Niyama (2005); Baker e Barbu (2007); Ding et al. (2005); e Zeff (2007), entre outros. As principais diferenças estão relacionadas a fatores econômicos e culturais (Barker e Barbu, 2007), diferenças entre países (Ding et al., 2005), diferenças entre sistemas legais (Niyama et al., 2005), linguagem, educação, inflação (Niyama, 2005), cultura contábil, cultura de auditoria e regulatória (Zeff, 2007).

Dentre os autores acima citados, Nobes (1998) apresentou uma listagem extensa de fatores que podem ocasionar as diferenças entre os padrões e práticas contábeis.

Nobes (1998) considera o modelo contábil como o conjunto de práticas utilizadas em uma demonstração contábil publicada. Para o autor, os modelos contábeis se diferem por alguns motivos. Nobes (1998) buscou determinar as razões para as divergências entre os modelos contábeis, chegando à conclusão de que a variação dos modelos ocorre no nível das entidades, ou seja, as variações podem ocorrer dentro de um mesmo país. 
Através de uma revisão da literatura até então existente, Nobes (1998) listou 17 (dezessete) principais razões apontadas pelos autores pesquisados para as diferenças entre modelos contábeis, a saber: a natureza da propriedade dos negócios, o sistema financeiro, a herança colonial, as invasões, a tributação, inflação, o nível educacional, idade e tamanho das empresas de serviços contábeis, estágio de desenvolvimento econômico, sistema jurídico-legal, cultura, história, geografia, língua, influência da teoria, sistemas políticos, clima social, religião e acidentes.

Apesar da extensa lista de razões, Nobes (1998) afirmava que tais estudos eram em sua maioria intuitivos, sem embasamento empírico adequado. Ele passou então a analisar os modelos contábeis dominantes de cada país, assim entendidos como os utilizados pelas entidades que englobam a maior parte da atividade econômica do país específico. Com base nessa análise, ele propôs um modelo classificatório, partindo do princípio de que, em países considerados culturalmente autossuficientes, ou seja, onde as instituições foram desenvolvidas localmente (as chamadas antigas metrópoles), a principal razão para as variações entre os sistemas contábeis é o propósito das publicações. O modelo identificou ainda que países culturalmente dominados, tais como ex-colônias e países subdesenvolvidos, tendem a adotar o sistema de suas antigas metrópoles.

Nobes (1998) afirma que os fatores que determinam o propósito das publicações em países culturalmente autossuficientes são o tipo de financiadores dominantes (se são internos ou externos), e a principal fonte de financiamento externo das entidades (se são do mercado de crédito ou do mercado de capitais). Como financiadores internos, entende-se por aqueles que possuem a capacidade de obter informações junto à administração da entidade de modo oportuno e frequente, tais como acionistas majoritários, bancos e governos. Já com relação aos financiadores externos, entende-se por aqueles que não pertencem à direção da entidade, nem possuem com ela um relacionamento privilegiado que lhes permita obter informações oportunas e frequentes, tais como os acionistas minoritários. Quanto às principais fontes de financiamento, os países foram classificados de acordo com sua predominância, ou seja, países onde as entidades buscam financiamento externo principalmente junto ao sistema bancário, com ou sem subsídios governamentais, e onde as entidades são financiadas principalmente pelo mercado de crédito. $\mathrm{O}$ mercado de capitais constitui outra opção de financiamento das entidades. Um resumo do modelo proposto pode ser observado pela seguinte matriz:

Tabela 1: Determinantes do propósito das publicações

\begin{tabular}{c|c|c}
\hline \multirow{2}{*}{ Financiadores Dominantes } & \multicolumn{2}{|c}{ Principal fonte de financiamento externo } \\
\cline { 2 - 3 } & Mercado de Crédito & Mercado de Capitais \\
\hline Internos & I & II \\
\hline Externos & III & IV \\
\hline
\end{tabular}

Fonte: Adaptado de Nobes (1998)

Nobes (1998) assume que os cenários mais comuns são o I e o IV, associando uma classe de modelos contábeis a cada um: o cenário I implica na chamada Classe B de modelos; o cenário IV implica na Classe A de modelos. Os modelos contábeis de Classe A são associados a cenários de financiamento externo através do mercado de capitais, que apresentam as seguintes características: voltados para usuários externos (teoricamente com maior nível de evidenciação), eles visam reportar o desempenho das entidades e permitir a projeção dos fluxos futuros de caixa. Os modelos contábeis de Classe A, com essas características, identificam-se claramente com os modelos contábeis de países anglo-saxões. Já os modelos contábeis de Classe B são associados aos cenários de financiamento externo através do mercado de crédito, e apresentam 
as seguintes características: voltados para usuários internos, eles buscam "proteger" os credores através da aplicação de maior prudência no cálculo dos lucros. Os modelos contábeis classe B, com essas características, identificam-se com os modelos contábeis da Europa Continental.

Com base na avaliação desses determinantes, Nobes (1998) enuncia cinco proposições sobre os modelos contábeis:

P1 - O modelo contábil dominante de um país culturalmente autossuficiente com cenário IV pertence à Classe $\mathrm{A}$;

P2 - O modelo contábil dominante de um país culturalmente autossuficiente com cenário I pertence à Classe $\mathrm{B}$;

P3 - Um país culturalmente dominado possui um modelo contábil importado de sua metrópole, independentemente de seu cenário;

P4 - Quando um país migra do cenário I para o IV, seu modelo contábil migra da Classe B para a A;

P5 - Entidades em países onde predomina a Classe B, e que buscam financiamento em países onde predomina a Classe A, passam a adotar os modelos contábeis da Classe A.

Porém, fica claro que o modelo proposto por Nobes não explica totalmente a situação atual do modelo contábil adotado no Brasil, que passa por regime de transição para a adoção completa das normas internacionais de contabilidade emitidas pelo IASB. Tem-se atualmente um modelo que claramente pertence à Classe $\mathrm{A}$, porém com estrutura de financiamento das entidades, em sua maioria, através do mercado de crédito. Esse cenário se deve ao desenvolvimento ainda pequeno do mercado de capitais brasileiro, além da alta concentração acionária das empresas listadas.

O trabalho de Weffort (2005) apresenta um estudo da situação do Brasil, na época, em relação à chamada harmonização contábil internacional. Nesse estudo, são discutidas as influências das forças de mercado, do sistema jurídico, do sistema educacional dos profissionais contábeis e dos fatores culturais no modelo contábil brasileiro. Apesar de o modelo contábil brasileiro atual estar claramente definido e delineado, em decorrência do processo de convergência para as normas emitidas pelo IASB, vale a pena revisitar alguns pontos do trabalho citado, devido à relevância das constatações para o objetivo do presente estudo, as quais podem auxiliar nas conclusões sobre os resultados que serão evidenciados ao final.

Weffort (2005) cita que uma das causas usualmente apontadas para as divergências entre os modelos contábeis são as características e necessidades dos usuários das demonstrações contábeis (forças de mercado). Assim, o atual cenário de globalização econômica, com as empresas atuando nos mercados de diversos países, favorece a busca pela harmonização/ convergência entre os modelos contábeis.

Com relação à harmonização, Weffort (2005) cita um ponto de extrema relevância para o presente estudo, que é a contabilidade de fato (de facto) e a de direito (de jure), não necessariamente coincidentes. A contabilidade de direito representa a consistência na forma (ou normas), e a de fato representa consistência na aplicação (ou práticas). A contabilidade de direito trata da uniformidade da regulação contábil, da convergência entre as normas, enquanto a contabilidade de fato diz respeito à adoção na prática cotidiana das empresas (Weffort, 2005; Tay e Parker, 1990 in Carmo et al. , 2011). Como se verá adiante, com relação às normas e práticas sobre taxas de depreciação adotadas por empresas brasileiras, prevalecia a utilização de taxas de depreciação definidas na legislação tributária. Com o advento da Lei 11.638/07 e 
consequente processo de convergência, essa realidade mudou, sendo incentivada a adoção de taxas que refletissem a real vida útil econômica do bem a ser depreciado.

O sistema jurídico também é apontado por Weffort (2005) como justificativa para as divergências entre os modelos contábeis. No ocidente predominam duas espécies de sistemas jurídicos: o consuetudinário (common law) e o codificado (code law). Lopes e Martins (2005) oferecem um resumo sobre as principais influências comumente apontadas dos sistemas jurídicos sobre os modelos contábeis:

Tabela 2: Influências dos sistemas jurídicos sobre os modelos contábeis

\begin{tabular}{c|c|c}
\hline Características & Common Law & Code Law \\
\hline Principal fonte do direito & Costume & Lei \\
\hline Regulação Contábil & Menos intensa, a cargo da iniciativa privada & Mais intensa, a cargo do estado \\
\hline Reconhecimento & Pela essência econômica & Pela forma jurídica \\
\hline Mensuração & Valor Justo (Fair Value) & Custo histórico \\
\hline Evidenciação & Maior disclosure & Menor disclosure \\
\hline
\end{tabular}

Fonte: Adaptado de Lopes e Martins (2005).

Com relação à tabela anterior, o Brasil, mais uma vez devido ao processo de convergência às normas do IASB, passa por uma situação interessante: É um país com sistema jurídico codificado, porém com legislação societária e normatização contábil com características de países com sistemas jurídicos baseados nos costumes. Os contadores brasileiros estão acostumados a normas locais expressas e definidas em termos codificados e bastante solenizados. Já a linguagem anglo-saxônica dos pronunciamentos internacionais, aos quais deveremos aderir, é extremamente complexa e exige grande grau de subjetivismo e análise para ser entendida (Iudícibus, 2007). Para tanto, foi necessária a modificação do artigo 177, e seus parágrafos, pela Lei 11.638/07, para que o país pudesse convergir para as normas internacionais de contabilidade.

O sistema educacional e profissional contábil brasileiro também é apontado por Weffort (2005), ao afirmar que as práticas contábeis podem ser influenciadas pelas características dos responsáveis pela elaboração das demonstrações contábeis. Os estudos conduzidos abordavam a seguinte questão: o sistema educacional profissional contábil favorece a harmonização da posição brasileira em relação à internacional? Após avaliar as estruturas curriculares dos cursos de graduação e pós-graduação em contabilidade no país, além dos conteúdos de teses, de dissertações e de periódicos científicos e profissionais, Weffort chegou à conclusão de que o sistema educacional profissional brasileiro não favorecia os esforços de harmonização contábil. Com a introdução do processo de convergência no Brasil, os estudantes, educadores e profissionais da área contábil necessitam de ampla readequação (talvez até reeducação) às novas normas contábeis, que diferem conceitualmente dos conjuntos de normas até então vigentes no país.

Weffort (2005) cita principalmente dois estudos (HOFSTED, 1984; GRAY, 1988) como base para a argumentação de que fatores culturais também influenciam as práticas contábeis de determinados países. Hofsted identificou quatro elementos estruturais do sistema cultural que afetam os negócios: individualismo, aversão à incerteza, masculinidade e distância do poder. No Brasil, segundo esse estudo, prevaleciam as dimensões culturais de coletivismo, forte aversão à incerteza, grande distância do poder e feminilidade, o que aproximaria o Brasil de países como Espanha, Argentina, Turquia Irã e Grécia. Já o estudo de Gray, incorporou “valores contábeis” ao estudo de Hofsted. Foram identificadas quatro dimensões de valores contábeis: profissionalismo, uniformidade, conservadorismo e sigilo. No Brasil, segundo Gray, predominariam os seguintes valores contábeis: profissionalismo, uniformidade, conservadorismo e sigilo (no mesmo perfil 
estariam Argentina, Bélgica, Espanha, França e Itália). A presença maior do profissionalismo no Brasil, atrelado à tendência de adoção de mecanismos legais mais ágeis (apesar do sistema jurídico brasileiro ser codificado), podem ser indícios dos caminhos tomados pelo Brasil sobre o processo de convergência às normas do IASB. A convergência de fato e de direito pode estar atrelada a valores culturais.

\subsection{A evolução da legislação societária brasileira e o processo de convergência às normas internacionais de contabilidade no Brasil}

A Lei das Sociedades Anônimas (6.404/76) não apresentava alterações importantes em seu capítulo XV (capítulo que trata do exercício social e demonstrações financeiras) até a sanção da Lei 11.638/07, que instituiu várias modificações nos padrões de contabilidade até então vigentes no país.

Segundo Braga e Almeida (2008), esse marco evolutivo da contabilidade no Brasil teve sua origem em novembro de 1990, quando o então presidente da Comissão de Valores Mobiliários (CVM), Dr. Ariosvaldo Mattos Filho, criou três comissões de especialistas para revisar e propor alterações nas Leis 6.385/76 e 6.404/76. A Comissão Jurídica foi presidida pelo Dr. José Luiz Bulhões Pedreira; a Comissão de Mercado de Valores Mobiliários pelo Prof. Mário Henrique Simonsen; e a Comissão Contábil pelo Prof. Sérgio de Iudícibus. Em 31 de Outubro de 2001 foi sancionada a Lei 10.303 sem a inclusão da matéria contábil incluída no projeto original de lei. A proposta de reformulação das normas contábeis passou, então, a integrar o projeto de lei específico (3.741/2000), que tinha a finalidade maior de possibilitar o processo de convergência das normas contábeis brasileiras aos padrões internacionais de contabilidade, além de aumentar o grau de transparência das demonstrações contábeis em geral.

Após a Lei 11.638/07, ainda foi sancionada a Lei 11.941/09 (conversão da Medida Provisória 449/08 em lei), que também trata de assuntos relevantes na área contábil.

Com relação ao tema proposto no presente estudo, é importante ressaltar os seguintes itens da Lei 11.638/07:
"Art. 177.
$\S 5^{\circ}$ As normas expedidas pela Comissão de Valores Mobiliários a que se refere o $\S$ $3 \underline{\text { o }}$ deste artigo deverão ser elaboradas em consonância com os padrões internacionais de contabilidade adotados nos principais mercados de valores mobiliários.
$\S 6 \underline{0}$ As companhias fechadas poderão optar por observar as normas sobre demonstrações financeiras expedidas pela Comissão de Valores Mobiliários para as companhias abertas.
$\S 7 \underline{\text { o }}$ Os lançamentos de ajuste efetuados exclusivamente para harmonização de normas contábeis, nos termos do $\S 2 \underline{\text { o }}$ deste artigo, e as demonstrações e apurações com eles elaboradas não poderão ser base de incidência de impostos e contribuições nem ter quaisquer outros efeitos tributários."

$\mathrm{O} \S 5^{\circ}$ do art. 177 abre caminho para que a CVM elabore normas em consonância com os padrões internacionais de contabilidade (o que já estava sendo feito). Já o $\S 7^{\circ}$ visa dar fim ao conflito entre contabilidade "societária" e contabilidade "fiscal", estabelecendo que qualquer ajuste necessário ao processo de convergência não deve ensejar incidência de tributos.

Já com relação às alterações da Lei 6.385/76 trazidas pela Lei 11.638/07, cabe ressaltar o seguinte: 


\begin{abstract}
"Art. $5^{\circ}$ - Inclusão do Art. 10-A - A Comissão de Valores Mobiliários, o Banco Central do Brasil e demais órgãos e agências reguladoras poderão celebrar convênio com entidade que tenha por objeto o estudo e a divulgação de princípios, normas e padrões de contabilidade e de auditoria, podendo, no exercício de suas atribuições regulamentares, adotar, no todo ou em parte, os pronunciamentos e demais orientações técnicas emitidas.

Parágrafo único. A entidade referida no caput deste artigo deverá ser majoritariamente composta por contadores, dela fazendo parte, paritariamente, representantes de entidades representativas de sociedades submetidas ao regime de elaboração de demonstrações financeiras previstas nesta Lei, de sociedades que auditam e analisam as demonstrações financeiras, do órgão federal de fiscalização do exercício da profissão contábil e de universidade ou instituto de pesquisa com reconhecida atuação na área contábil e de mercado de capitais."
\end{abstract}

Apesar de não citar explicitamente a entidade, fica claro o direcionamento do artigo acima para a celebração de convênios entre órgãos reguladores e o CPC - Comitê de Pronunciamentos Contábeis.

O CPC é resultado da união das seguintes entidades: Abrasca, Apimec Nacional, Bovespa, Conselho Federal de Contabilidade, Fipecafi e Ibracon, em função das necessidades de convergência internacional das normas contábeis e centralização de emissão de normas dessa natureza.

Criado pela Resolução CFC 1.055/05, o CPC tem como objetivo “o estudo, o preparo e a emissão de Pronunciamentos Técnicos sobre os procedimentos de Contabilidade e a divulgação de informações dessa natureza, para permitir a emissão de normas pela entidade reguladora brasileira, e visando à centralização e uniformização do seu processo de produção, sempre levando em consideração a convergência da Contabilidade Brasileira aos padrões internacionais". O CPC produz Pronunciamentos Técnicos, Orientações e Interpretações, com direcionamento explícito de convergência com as normas internacionais de contabilidade, produzidas pelo IASB.

\title{
2.3 Depreciação de bens do ativo imobilizado e disposições legais sobre o tema
}

Iudícibus (2004) traz uma definição da American Accounting Association, de 1957, quanto aos fatores aos quais é devida a depreciação:

\footnotetext{
"Qualquer declínio no potencial de serviços e outros ativos não correntes deveria ser reconhecido nas contas do período em que tal declínio ocorre... O potencial de serviços dos ativos pode declinar por causa de... deterioração física gradual ou abrupta, consumo dos potenciais de serviços através do uso, mesmo que nenhuma mudança física seja aparente, ou deterioração econômica por causa da obsolescência ou de mudança na demanda dos consumidores".
}

O CPC 27 sobre ativo imobilizado define depreciação como a "alocação sistemática do valor depreciável de um ativo ao longo da sua vida útil”".

Em essência, a depreciação é mais um processo alocativo de custos ativados, do que um processo valorativo do ativo. Os elementos que integram o Ativo Imobilizado têm um período limitado de vida útil econômica. Apesar de o declínio no potencial de serviços não ser constante, a contabilidade necessita de uma metodologia para reconhecimento dessa perda. Iudíciubs, et.al (2010) afirmam que o custo de tais ativos (imobilizado) deve ser alocado de maneira sistemática 
aos exercícios beneficiados por seu uso no decorrer de sua vida útil econômica.

O art.183 da Lei 6.404/76, que rege os critérios de avaliação do Ativo, em seu $\S 2^{\circ}$ (com redação dada pela Lei 11.638/07) prevê que "a diminuição do valor dos elementos dos ativos imobilizado [...] será registrada periodicamente nas contas de:

a) Depreciação, quando corresponder à perda do valor dos direitos que têm por objeto bens físicos sujeitos a desgaste ou perda de utilidade por uso, à ação da natureza ou à obsolescência;"

Adicionalmente, o mesmo artigo, em seu $\S 3^{\circ}$ (com redação dada pela Lei 11.638/07) dispõe: “A companhia deverá efetuar, periodicamente, análise sobre a recuperação dos valores registrados no imobilizado, no intangível e no diferido, a fim de que sejam:

$$
\mathrm{I}-[\ldots]
$$

II - revisados e ajustados os critérios utilizados para a determinação da vida útil econômica estimada e para o cálculo da depreciação, exaustão e amortização."

Como se pode observar, o objetivo do artigo acima não é o de conceituar a depreciação, mas sim definir critérios de avaliação de ativos. Porém, fica claro pela leitura que o legislador leva em consideração os conceitos econômicos de avaliação dos ativos, bem como de perda de potencial de prestação de serviços.

No Brasil, porém, a contabilidade das empresas sempre apresentou forte direcionamento para alguns critérios definidos em legislações fiscais específicas. A utilização de taxas de depreciação fiscais constitui um caso claro desta conduta. Devido aos limites de dedutibilidade das despesas de depreciação aceitos pelo Fisco, as empresas que têm o IRPJ e a CSLL apurados pelo lucro real estão condicionadas a utilizar taxas de depreciação por ele definidas,.

Os critérios fiscais básicos de depreciação estão consolidados no Regulamento do Imposto de Renda (Decreto $n^{\circ}$ 3000/99), através de seus artigos 305 a 323. A relação dos bens e suas respectivas vidas úteis e taxas máximas de depreciação constam das Instruções Normativas da SRF 162 (31.12.1998) e 130 (10.11.1999). As taxas máximas anuais de depreciação admitidas pelo Fisco são geralmente para uso normal dos bens em um turno de oito horas diárias, e são apresentadas a seguir:

Tabela 4: Taxas máximas de depreciação usualmente admitidas pelo Fisco

\begin{tabular}{c|c|c}
\hline & Taxa anual & Anos de Vida útil \\
\hline Edifícios & $4 \%$ & 25 \\
\hline Máquinas e Equipamentos & $10 \%$ & 10 \\
\hline Instalações & $10 \%$ & 10 \\
\hline Móveis e Utensílios & $10 \%$ & 10 \\
\hline Equipamentos de Informática & $20 \%$ & 5 \\
\hline Sistema de processamento de dados & $20 \%$ & 5 \\
\hline Veículos & $20 \%$ & 5 \\
\hline
\end{tabular}

Fonte:: Adaptado de Iudícibus et.al.

É possível ainda que o Fisco admita taxas de depreciação diferenciadas, desde que corroboradas por laudos periciais do Instituto Nacional de Tecnologia, ou de outra entidade oficial de pesquisa científica ou tecnológica, conforme previsto no art.310, $\S 2^{\circ}$, do Decreto $\mathrm{n}^{\mathrm{o}}$ 3000/99. Caso a empresa opere em mais de um turno, a depreciação acelerada, em função do número de horas diárias de operação, poderá ser utilizada. 


\section{METODOLOGIA DE PESQUISA}

Para o presente estudo, foram selecionadas 38 empresas do Setor de Bens Industriais, conforme classificação da BM\&F Bovespa, que classifica as empresas listadas em setores específicos de atividade, representando assim uma amostra intencional de dados, o que também resulta numa limitação desta pesquisa.

O setor de Bens Industriais foi selecionado por se tratar essencialmente de indústrias que produzem bens de capital e necessitam, portanto, de altos investimentos em ativos imobilizados, implicando em maiores valores depreciados.

A expectativa na seleção é de que o tratamento contábil das depreciações nesse setor fosse mais acurado, devido à importância que esses valores representam nos ativos e resultados das empresas pesquisadas. A seguir, são apresentados os subsetores, segmentos e empresas pesquisadas.

Tabela 5: Empresas do Setor de Bens Industriais pesquisadas

\begin{tabular}{|c|c|c|c|}
\hline Nr. Ordem & Nome da Empresa & Nr. Ordem & Nome da Empresa \\
\hline 1 & Lark S.A. Máquinas e Equipamentos & 20 & Autometal S.A. \\
\hline 2 & Minasmáquinas S.A. & 21 & DHB Indústria e Comércio S.A. \\
\hline 3 & WLM - Indústria e Comércio S.A. & 22 & Fras-le S.A. \\
\hline 4 & Metalfrio Solutions S.A. & 23 & Iochpe Maxion S.A. \\
\hline 5 & Forjas Taurus S.A. & 24 & Mahle-Metal Leve S.A. \\
\hline 6 & Caterpillar Inc.* & 25 & Marcopolo S.A. \\
\hline 7 & Electro Aço Altona S.A. & 26 & Metalúrgica Riosulense S.A. \\
\hline 8 & Metisa Metalúrgica Timboense S.A. & 27 & Plascar Participações Industriais S.A. \\
\hline 9 & Baumer S.A. & 28 & Randon S.A. Implementos e Participações \\
\hline 10 & Bardella S.A. Indústrias Mecânicas & 29 & Recrusul S.A. \\
\hline 11 & Indústrias Romi S.A. & 30 & Tupy S.A. \\
\hline 12 & Inepar S.A. Indústria e Construções & 31 & Wetzel S.A. \\
\hline 13 & Kepler Weber S.A. & 32 & Wiest S.A. \\
\hline 14 & Nordon Indústrias Metalúrgicas S.A. & 33 & Cia. De Recuperação Secundária* \\
\hline 15 & Lupatech S.A. & 34 & Contax Participações S.A. \\
\hline 16 & Schulz S.A. & 35 & CSU Cardsystem S.A. \\
\hline 17 & Weg S.A. & 36 & DTCOM - Direct to Company S.A. \\
\hline 18 & Embraer S.A. & 37 & Mills Estruturas e Serviços de Engenharia S.A. \\
\hline 19 & Cobrasma S.A. & 38 & Valid Sol. E Serv. Seg. Meios Pag. Ident. S.A. \\
\hline
\end{tabular}

Fonte: BM\&F bovespa

*Algumas empresas constavam da classificação, mas não possuíam dados contábeis divulgados no sítio da BM\&F Bovespa. 
Apresentadas as empresas objeto de estudo, segundo tabela de número 5, passou-se à alocação das mesmas em conformidade com o respectivo subsetor e segmento:

Tabela 6: Empresas separadas por Subsetor e Segmento

\begin{tabular}{c|c}
\hline Subsetor e Segmento & Empresas \\
\hline Subsetor Comércio & 1 \\
\hline Segmento Máquinas e Equipamentos & 2 e 3 \\
\hline Segmento Material de Transporte & \\
\hline Subsetor Equipamentos Elétricos & 4 \\
\hline Segmento Equipamentos Elétricos & 5 \\
\hline Subsetor Máquinas e Equipamentos & 6 a 8 \\
\hline Segmento Armas e Munições & 9 \\
\hline Segmento Máq. e Equip. Construção e Agrícolas & 10 a 14 \\
\hline Segmento Máquinas e Equip. Hospitalares & 15 a 17 \\
\hline Segmento Máquinas e Equip. Industriais & 18 \\
\hline Segmento Motores, Compressores e Outros & 19 \\
\hline Subsetor Material de Transporte & 20 a 32 \\
\hline Segmento Material Aeronáutico & \\
\hline Segmento Material Ferroviário & 33 a 38 \\
\hline Segmento Material Rodoviário & \\
\hline Subsetor Serviços & \\
\hline Segmento Serviços Diversos & \\
\hline
\end{tabular}

Fonte:BM\&F bovespa

Após a seleção das empresas, foram verificadas as notas explicativas dos exercícios de 2008, 2009 e 2010, especificamente no tocante às taxas de depreciação praticadas para elaboração das demonstrações contábeis. Essas notas explicativas foram obtidas diretamente nos sítios da BM\&F Bovespa e CVM - Comissão de Valores Mobiliários.

Os exercícios foram selecionados de acordo com os eventos legais que alteraram a legislação societária brasileira, mais especificamente no tocante à avaliação de ativos imobilizados, conforme já detalhado anteriormente no item 2.4.

A expectativa era de que, para o exercício de 2008, as empresas estivessem praticando taxas fiscais de depreciação, devido à falta de normatização alternativa vigente. Já para 2009, a expectativa era de que as empresas já adotassem taxas condizentes com a vida útil econômica dos bens, pois tanto o CPC quanto a CVM já haviam editado normas sobre o assunto, bem como para a adoção inicial das normas emitidas pelo IASB (IFRS). Para 2010, o primeiro ano de divulgação em IFRS total, inclusive com reclassificação inicial e final de 2009 para fins comparativos com 2010, a expectativa era de que as taxas utilizadas já observassem completamente a vida útil econômica dos bens.

Os grupos de bens do ativo imobilizado pesquisados foram edificações e imóveis, máquinas e equipamentos, móveis e utensílios, equipamentos de informática e veículos, tendo em vista a maior ocorrência desses tipos de bens na maioria das empresas pesquisadas Outros tipos de bens eram menos frequentes, havendo ainda a nomenclatura "outros" sem maiores especificações ao que se referiam.

No apêndice estão as tabelas com os resumos das taxas de depreciação encontradas nas empresas. Para fins comparativos e melhor visualização dos resultados, as taxas fiscais de depreciação de cada item são apresentadas. 
Para fins de simplificação, nas tabelas seguintes foi lançado somente o número de ordem das empresas, conforme listado na tabela 5 . A análise dessas tabelas permite chegar às seguintes conclusões:

1. Os dados contábeis das empresas com os números de ordem 6 e 33, que constavam inicialmente na classificação da BM\&F Bovespa, não foram disponibilizados.

2. As empresas com os números de ordem 9 e 14 não tinham informações detalhadas sobre a vida útil dos bens ou taxas de depreciação utilizadas, não sendo possível qualquer conclusão sobre suas práticas de depreciação.

Portanto, para fins de obtenção e análise dos percentuais de ocorrência que se evidencia a seguir, utilizou-se, como número de empresas válidas para o estudo, 34 empresas.

\section{ANÁLISE DOS DADOS}

Todas as empresas utilizaram o método linear de depreciação (ou método das quotas constantes), apesar da existência de métodos alternativos para cálculo, tais como método da soma dos dígitos dos anos, método das unidades produzidas e método das horas de trabalho.

Várias empresas utilizavam exclusivamente taxas de depreciação fiscais para o exercício de 2008, conforme resumo abaixo. O percentual oferecido na tabela refere-se à comparação entre o número de ocorrências com o número total de empresas válidas analisadas.

Tabela 7: Empresas que utilizavam exclusivamente taxas fiscais de depreciação em 2008

\begin{tabular}{c|c|c}
\hline Nr. Ordem das Empresas & Quantidade & $\mathbf{\%}$ \\
\hline $2,10,11,13,15,19,21,22,23,25,26,29$ & 12 & $35,29 \%$ \\
\hline
\end{tabular}

Fonte: elaborada pelos autores

Algumas empresas também utilizaram amplamente as taxas fiscais de depreciação para o exercício de 2008, com exceção de um ou dois itens para os quais essas taxas não foram utilizadas. As seguintes empresas podem ser consideradas empresas que praticavam taxas fiscais de depreciação:

Tabela 8 : Empresas que utilizavam quase totalmente taxas fiscais de depreciação em 2008

\begin{tabular}{c|c|c}
\hline Nr. Ordem das Empresas & Quantidade & \% \\
\hline $1,4,5,7,8,16,20,24,28,31,35,36,38$ & 13 & $38,24 \%$ \\
\hline
\end{tabular}

Fonte: elaborada pelos autores

Ao se agrupar os percentuais das duas tabelas acima, pode-se concluir que 73,53\% das empresas pesquisadas utilizavam taxas fiscais de depreciação em 2008, o que confirma a afirmação de que essa era uma prática comum nas empresas brasileiras e que essa prática era claramente direcionada pela legislação fiscal.

Por exclusão, 9 empresas, ou 26,47\%, já utilizavam taxas de depreciação diferentes ou em intervalos diferentes das taxas previstas na legislação fiscal. A análise da evolução das taxas de depreciação dessas empresas leva à conclusão de que elas não levavam em consideração 
exclusivamente as taxas fiscais de depreciação, o que foi considerado salutar em termos de avaliação dos bens do ativo imobilizado. As empresas com essas práticas são as seguintes:

Tabela 9: Empresas que não utilizavam taxas fiscais de depreciação em 2008

\begin{tabular}{c|c|c}
\hline Nr. Ordem das Empresas & Quantidade & \% \\
\hline $3,12,17,18,27,30,32,34,37$ & 9 & $26,47 \%$ \\
\hline
\end{tabular}

Fonte: elaborada pelos autores

Para os anos de 2009 e 2010, as empresas acima continuaram utilizando taxas diferentes das taxas fiscais, e, em alguns casos, revisaram as taxas, alterando-as, o que evidencia cuidado quanto aos critérios de avaliação dos ativos imobilizados.

Porém, o objetivo do estudo era averiguar se as empresas, diante de uma situação de alteração da legislação e normatização vigentes, e com a possibilidade de adotar práticas alternativas, iriam adotar as novas práticas, promovendo uma contabilidade de fato e de direito plenamente idênticas, pelo menos quanto aos critérios de depreciação.

Avaliou-se então, quais das 25 empresas listadas nas tabelas 7 e 8 acima, alteraram as taxas de depreciação no exercício seguinte (2009). As empresas que alteraram suas taxas para o exercício de 2009 foram as seguintes:

Tabela 10 : Empresas que alteraram suas taxas de depreciação em 2009

\begin{tabular}{c|c|c}
\hline Nr. Ordem das Empresas & Quantidade & $\%$ \\
\hline $11,13,22,24,28$ & 5 & $20,00 \%$ \\
\hline
\end{tabular}

Fonte: elaborada pelos autores

A tabela acima indica que das 25 empresas que utilizaram taxas de depreciação fiscais em 2008, somente 5, ou 20\% delas, passaram a utilizar taxas diferentes das fiscais em 2009, apesar de haver normatização e previsão de sua utilização para o exercício de 2009. Esse baixo número de empresas talvez decorra do curto prazo de adequação às novas normas, o ano de 2009, já que para a adequação, há a necessidade de reavaliação técnica da vida útil dos ativos, o que pode demandar um tempo longo de trabalho.

Das 5 empresas constantes da tabela 10, as empresas 11, 13, 22 e 28 alteraram mais de uma vez suas taxas de depreciação para o exercício de 2010, o que evidencia acompanhamento constante da vida útil dos bens de seus ativos imobilizados. A empresa 24 voltou em 2010 a utilizar as taxas de depreciação fiscais.

Por exclusão, 20 empresas não alteraram suas taxas de depreciação em 2009, ou seja, $80 \%$ das 25 empresas que utilizavam taxas fiscais em 2008. Essas empresas são as seguintes:

Tabela 11: Empresas que não alteraram suas taxas de depreciação em 2009

\begin{tabular}{|c|c|c|}
\hline Nr. Ordem das Empresas & Quantidade & $\%$ \\
\hline $1,2,4,5,7,8,10,15,16,19,20,21,23,25,26,29,31,35,36,38$ & 20 & $80,00 \%$ \\
\hline
\end{tabular}

Fonte: elaborada pelos autores

A próxima etapa da análise foi averiguar quais das 20 empresas, que ainda não haviam alterado suas taxas até 2009, alteraram efetivamente essas taxas para o exercício de 2010, o que configuraria a adoção da nova normatização contábil. As empresas que alteraram suas taxas para 2010 foram as seguintes: 
Tabela 12: Empresas que alteraram suas taxas de depreciação em 2010

\begin{tabular}{|c|c|c|}
\hline Nr. Ordem das Empresas & Quantidade & $\%$ \\
\hline $5,7,8,10,15,16,20,21,23,25,26,31,35,36$ & 14 & $70,00 \%$ \\
\hline
\end{tabular}

Fonte: elaborada pelos autores

Conforme análise da tabela acima, das 20 empresas que ainda não haviam adotado taxas diferentes das taxas fiscais até 2009, 14 delas modificaram suas taxas de depreciação em 2010, o que evidencia também a adoção da nova normatização contábil. A empresa de número 29 não disponibilizou os dados de 2010 para análise.

Por exclusão, somente 5 empresas, das 20 restantes, não optaram por rever suas taxas de depreciação, e continuaram em 2010 a adotar taxas de depreciação idênticas às taxas fiscais. São elas:

Tabela 13: Empresas que não alteraram suas taxas de depreciação em 2010

\begin{tabular}{c|c|c}
\hline Nr. Ordem das Empresas & Quantidade & \% \\
\hline $1,2,4,19,38$ & 5 & $25,00 \%$ \\
\hline
\end{tabular}

Fonte: elaborada pelos autores

Ao confrontarmos o número de empresas que não alteraram suas taxas de depreciação até 2010, com o total de empresas válidas para análise (34 empresas), tem-se um percentual de não observação das novas normas contábeis de 14,71\%, o que pode ser considerado um percentual relativamente baixo de não observância de normas.

Apesar de ser baixo, esse percentual evidencia a existência no Brasil de práticas fiscais que ainda influenciam as práticas contábeis nas empresas, pelo menos no tocante ao universo de empresas analisado e às taxas de depreciação. Cabe reforçar que pela análise das notas explicativas não foi possível identificar os motivos da manutenção das taxas de depreciação de acordo com os percentuais máximos admitidos pela legislação fiscal. Tampouco nenhuma observação foi realizada nos relatórios dos auditores independentes dessas empresas, o que permite inferir que as possíveis variações no percentual de depreciação não sejam materiais. Apesar disso, mesmo que tais possíveis distorções sejam imateriais não se deve interpretar que as empresas aplicaram as práticas contábeis de modo adequado.

\section{CONSIDERAÇÕES FINAIS}

As taxas de depreciação deveriam refletir a vida útil econômica do bem, não cabendo a adoção de qualquer metodologia definida por legislação fiscal. A adoção de taxas de depreciação fiscais prevalecia entre as empresas brasileiras. O presente trabalho visou identificar se as empresas abertas brasileiras do setor de bens industriais, diante do processo de convergência para as normas internacionais de contabilidade, passariam a adotar taxas de depreciação condizentes com a vida útil econômica dos bens do ativo imobilizado, fazendo com que a contabilidade de fato e de direito fossem coincidentes, pelo menos no tocante às taxas de depreciação.

Os resultados da pesquisa evidenciaram que a maioria das empresas (escopo do trabalho) brasileiras listadas em bolsa do setor de bens industriais, utilizava, até 2008, taxas de depreciação fiscais. A partir daí, com a vigência de novo ordenamento contábil, as empresas passaram gradualmente a adotar os critérios de taxas de depreciação baseados na vida útil 
econômica dos bens, para os anos de 2009 e 2010.

Essas constatações mostram que, apesar da possibilidade de tratamentos alternativos às taxas de depreciação, grande parte das empresas estudadas aderiu às normas internacionais de contabilidade, pelo menos no tocante às taxas de depreciação.

Porém, a existência de empresas que ainda adotam as taxas fiscais evidencia que o processo de convergência ainda não ocorre com totalidade. A não adoção pode ser explicada em parte pelas diferenças naturais de padrões contábeis e pela percepção dos participantes desse processo, conforme já citado nos estudos de Nobes (1998), Weffort (2005) e Kvaal e Nobes (2010).

Seria necessário um aprofundamento da pesquisa sobre os reais motivos que levaram as empresas a não adotarem novas taxas. Para maior conforto sobre as conclusões do processo de convergência, novos estudos nesse sentido poderão ser conduzidos com a ampliação da amostra. Adicionalmente, poderiam ser desenvolvidos estudos sobre todas as práticas alternativas que a adoção das IFRS permite, bem como a adoção ou não dessas práticas alternativas por empresas brasileiras.

\section{REFERÊNCIAS}

BAKER, C. R.; BARBU, E. M.. Trends in research on international accounting harmonization. The International Journal of Accounting, V. 42, n. 3, p. 272-304. 2007.

BM\&F BOVESPA. Demonstrações Financeiras Padronizadas - Notas Explicativas. Disponível em:<www.bmfbovespa.com.br> . Acessado em: 30 de junho de 2011.

BRAGA, Hugo Rocha; ALMEIDA, Marcelo Cavalcanti. Mudanças Contábeis na Lei Societária. São Paulo: Atlas, 2008.

BRASIL. Lei n. 6.404, de 15 de dezembro de 1976. Dispõe sobre as sociedades por ações.

BRASIL. Decreto n.3.000 de 26 de Março de 1999. RIR - Regulamento do Imposto de Renda/99.

BRASIL. Lei n. 11.638, de 28 de dezembro de 2007. Altera e revoga dispositivos da Lei no 6.404, de 15 de dezembro de 1976, e da Lei no 6.385, de 7 de dezembro de 1976, e estende às sociedades de grande porte disposições relativas à elaboração e divulgação de demonstrações financeiras.

BRASIL. Lei n. 11.941, de 27 de Maio de 2009. Altera dispositivos da Lei no 6.404, de 15 de dezembro de 1976, e da Lei no 6.385, de 7 de dezembro de 1976.

CARMO, Carlos Henrique Silva do; RIBEIRO, Alex Mussoi; CARVALHO, Luiz Nelson Guedes de. Convergência de fato ou de direito? A influência do sistema jurídico na aceitação das normas internacionais para pequenas e médias empresas. Revista de Contabilidade de Finanças - USP, São Paulo, v. 22, n. 57, p. 242-262, 2011.

CONSELHO FEDERAL DE CONTABILIDADE. Resolução n¹.055, de 07 de outubro de 2005. Cria o Comitê de Pronunciamentos Contábeis (CPC) e dá outras providências.

CPC - Comitê de Pronunciamentos Contábeis. CPC 27 - Ativo Imobilizado, de 26 de Junho de 2009. 
CVM, Comissão de Valores Mobiliários. Demonstrações Financeiras Padronizadas - Notas Explicativas. Disponível em: <www.cvm.gov.br>. Acessado em: 30 de junho de 2011.

DING, Y.; JEANJEAN, T.; STOLOWY, H.. Why do national GAAP differ from IAS? The role of culture. The International Journal of Accounting, V.40, n. 4, p.325-350, 2005.

HAIL, Luzi et al. Global Accounting Convergence and the Potential Adoption of IFRS by the U.S. (Part II): Political Factors and Future Scenarios for U.S. Accounting Standards. Accounting Horizons, v. 24, n. 4, p. 567-588, 2010.

HENDRIKSEN, Eldon S; VAN BREDA, Michael. Teoria da Contabilidade. São Paulo: Atlas, 1999.

IFRS Foundation. Quem somos e o que fazemos. Disponível em: <www.ifrs.org > Acessado em: 30 de junho de 2011.

IKUNO, Luciana Miyuki; NIYAMA, Jorge Katsumi; BOTELHO, Ducinéli Régis; SANTANA, Cláudio Moreira. CONTABILIDADE INTERNACIONAL: Uma Análise da produção científica sobre nos principais periódicos internacionais da área (2000 a 2009). $\mathbf{1 0}^{\circ}$ Congresso USP de Controladoria e Contabilidade. São Paulo, 2010.

IUDÍCIBUS, Sérgio de. Teoria da Contabilidade. 7 ed. São Paulo: Atlas, 2004.

IUDÍCIBUS, Sérgio de. Contabilidade: Entre uma e outras. Revista de Informação Contábil - RIC - Vol. 1, no 1 p. 1-6, 2007.

IUDÍCIBUS, Sérgio de; MARTINS, Eliseu; GELBCKE, Ernesto Rubens; SANTOS, Ariovaldo dos. Manual de Contabilidade Societária: aplicável a todas as sociedades de acordo com as normas internacionais e do CPC. São Paulo: Atlas, 2010.

LOPES, Alexsandro Broedel; MARTINS, Eliseu. Teoria da Contabilidade: Uma Nova Abordagem. Sao Paulo: Atlas, 2005.

KVAAL, Erlend; NOBES, Christopher. International differences in IFRS policy choice: a research note. Accounting and Business Research, v. 40, n. 2, p. 173-187, 2010.

NIYAMA, Jorge Katsumi; COSTA, Patrícia de Souza; BOTELHO, Ducinéli Régis. Principais Causas Das Diferenças Internacionais No Financial Reporting: Uma Pesquisa Empírica Em Instituições De Ensino Superior Do Nordeste E Centrooeste Do Brasil. Con Texto, Porto Alegre, v. 5, n. $8,2^{\circ}$ semestre 2005 .

NIYAMA, J. K.. Contabilidade Internacional. São Paulo: Atlas, 2005.

NOBES, Christopher. Towards a General Model of the Reasons for International Differences in Financial Reporting. ABACUS, v. 34, n. 2, p. 162-187, 1998.

RFB - Receita Federal do Brasil. Instrução Normativa SRF n.162, de 31 de dezembro de 1998.

RFB - Receita Federal do Brasil. Instrução Normativa SRF n.130, de 10 de novembro de 1999.

WEFFORT, Elionor Farah Jreige. O Brasil e a Harmonização Contábil Internacional: Influencias dos Sistemas Juridico e Educacional, da Cultura e do Mercado. Sao Paulo: Atlas, 2005.

ZEFF, S. A. . Some obstacles to global financial reporting comparability and convergence at a high level of quality. The British Accounting Review, V. 39, n. 4, p.290-302, dez/2007. 


\section{APÊNDICE - RESUMO DAS TAXAS DE DEPRECIAÇÃO UTILIZADAS PELAS EMPRESAS DE 2008 A 2010}

\begin{tabular}{|c|c|c|c|c|c|c|c|}
\hline & & \multicolumn{3}{|c|}{ Empresa 1} & \multicolumn{3}{|c|}{ Empresa 2} \\
\hline Bens do Imobilizado & Taxas Fiscais & 2008 & 2009 & 2010 & 2008 & 2009 & 2010 \\
\hline Edificações / Imóveis & $4 \%$ & $4,0 \%$ & $4,0 \%$ & $4,0 \%$ & $4,0 \%$ & $4,0 \%$ & $4,0 \%$ \\
\hline Máquinas e Equipamentos & $10 \%$ & $10 \%$ a $20 \%$ & $10 \%$ a $20 \%$ & $10 \%$ a $20 \%$ & $10,0 \%$ & $10,0 \%$ & $10,0 \%$ \\
\hline Móveis e Utensílios & $10 \%$ & $10,0 \%$ & $10,0 \%$ & $10,0 \%$ & $10,0 \%$ & $10,0 \%$ & $10,0 \%$ \\
\hline Equipam. Informática & $20 \%$ & $20,0 \%$ & $20,0 \%$ & $20,0 \%$ & $20,0 \%$ & $20,0 \%$ & $20,0 \%$ \\
\hline \multirow[t]{2}{*}{ Veículos } & $20 \%$ & $10,0 \%$ & $10,0 \%$ & $10,0 \%$ & $20,0 \%$ & $20,0 \%$ & $20,0 \%$ \\
\hline & & \multicolumn{3}{|c|}{ Empresa 3} & \multicolumn{3}{|c|}{ Empresa 4} \\
\hline Bens do Imobilizado & Taxas Fiscais & 2008 & 2009 & 2010 & 2008 & 2009 & 2010 \\
\hline Edificações / Imóveis & $4 \%$ & $1 \%$ a $10 \%$ & $1 \%$ a $10 \%$ & $1 \%$ a $10 \%$ & $4,0 \%$ & $4,0 \%$ & $4,0 \%$ \\
\hline Máquinas e Equipamentos & $10 \%$ & $1 \%$ a $25 \%$ & $1 \%$ a $25 \%$ & $1 \%$ a $25 \%$ & $11,0 \%$ & $11,0 \%$ & $11,0 \%$ \\
\hline Móveis e Utensílios & $10 \%$ & $1 \%$ a $33 \%$ & $1 \%$ a $33 \%$ & $1 \%$ a $33 \%$ & $10,0 \%$ & $10,0 \%$ & $10,0 \%$ \\
\hline Equipam. Informática & $20 \%$ & & & & & & \\
\hline \multirow[t]{2}{*}{ Veículos } & $20 \%$ & $1 \%$ a $25 \%$ & $1 \%$ a $25 \%$ & $1 \%$ a $25 \%$ & $20,0 \%$ & $20,0 \%$ & $20,0 \%$ \\
\hline & & \multicolumn{3}{|c|}{ Empresa 5} & \multicolumn{3}{|c|}{ Empresa 6} \\
\hline Bens do Imobilizado & Taxas Fiscais & 2008 & 2009 & 2010 & 2008 & 2009 & 2010 \\
\hline Edificações / Imóveis & $4 \%$ & $4,0 \%$ & $4,0 \%$ & $3,7 \%$ & & & \\
\hline Máquinas e Equipamentos & $10 \%$ & $10,0 \%$ & $10,0 \%$ & $5 \%$ a $6,67 \%$ & & & \\
\hline Móveis e Utensílios & $10 \%$ & $10 \%$ a $20 \%$ & $10 \%$ a $20 \%$ & $6,7 \%$ & & & \\
\hline Equipam. Informática & $20 \%$ & & & & & & \\
\hline \multirow[t]{2}{*}{ Veículos } & $20 \%$ & & & $16,6 \%$ a $20 \%$ & & & \\
\hline & & \multicolumn{3}{|c|}{ Empresa 7} & \multicolumn{3}{|c|}{ Empresa 8} \\
\hline Bens do Imobilizado & Taxas Fiscais & 2008 & 2009 & 2010 & 2008 & 2009 & 2010 \\
\hline Edificações / Imóveis & $4 \%$ & $4,0 \%$ & $4,0 \%$ & $4,0 \%$ & $4,0 \%$ & $4,0 \%$ & $2,4 \%$ \\
\hline Máquinas e Equipamentos & $10 \%$ & $10 \%$ a $20 \%$ & $10 \%$ a $20 \%$ & $5,6 \%$ & $20,0 \%$ & $20,0 \%$ & $16,4 \%$ \\
\hline Móveis e Utensílios & $10 \%$ & $10,0 \%$ & $10,0 \%$ & $11,1 \%$ & $10,0 \%$ & $10,0 \%$ & \\
\hline Equipam. Informática & $20 \%$ & $20,0 \%$ & $20,0 \%$ & $25,0 \%$ & & & \\
\hline \multirow[t]{2}{*}{ Veículos } & $20 \%$ & $20,0 \%$ & $20,0 \%$ & $25,0 \%$ & $20,0 \%$ & $20,0 \%$ & $13,6 \%$ \\
\hline & & \multicolumn{3}{|c|}{ Empresa 9} & \multicolumn{3}{|c|}{ Empresa 10} \\
\hline Bens do Imobilizado & Taxas Fiscais & 2008 & 2009 & 2010 & 2008 & 2009 & 2010 \\
\hline Edificações / Imóveis & $4 \%$ & & & & $4,0 \%$ & $4,0 \%$ & $2,7 \%$ \\
\hline Máquinas e Equipamentos & $10 \%$ & & & & $10,0 \%$ & $10,0 \%$ & $8,4 \%$ \\
\hline Móveis e Utensílios & $10 \%$ & & & & $10,0 \%$ & $10,0 \%$ & $10,0 \%$ \\
\hline Equipam. Informática & $20 \%$ & & & & $20,0 \%$ & $20,0 \%$ & $20,0 \%$ \\
\hline \multirow[t]{2}{*}{ Veículos } & $20 \%$ & & & & $20,0 \%$ & $20,0 \%$ & $20,0 \%$ \\
\hline & & \multicolumn{3}{|c|}{ Empresa 11} & \multicolumn{3}{|c|}{ Empresa 12} \\
\hline Bens do Imobilizado & Taxas Fiscais & 2008 & 2009 & 2010 & 2008 & 2009 & 2010 \\
\hline Edificações / Imóveis & $4 \%$ & $4,0 \%$ & $4,0 \%$ & $4,0 \%$ & $2,5 \%$ a $4 \%$ & $2,5 \%$ a $4 \%$ & $4,0 \%$ \\
\hline Máquinas e Equipamentos & $10 \%$ & $10,0 \%$ & $4 \%$ a $10 \%$ & $10 \%$ a $15 \%$ & $10 \%$ a $12,5 \%$ & $10 \%$ a $12,5 \%$ & $10 \%$ a $20 \%$ \\
\hline Móveis e Utensílios & $10 \%$ & $10,0 \%$ & $10,0 \%$ & $10,0 \%$ & $10 \%$ a $20 \%$ & $10 \%$ a $20 \%$ & $10,0 \%$ \\
\hline Equipam. Informática & $20 \%$ & $20,0 \%$ & $20,0 \%$ & $20,0 \%$ & & & $20,0 \%$ \\
\hline \multirow[t]{2}{*}{ Veículos } & $20 \%$ & $20,0 \%$ & $20,0 \%$ & $20,0 \%$ & & & $20,0 \%$ \\
\hline & & Empresa 13 & & & Empresa 14 & & \\
\hline Bens do Imobilizado & Taxas Fiscais & 2008 & 2009 & 2010 & 2008 & 2009 & 2010 \\
\hline Edificações / Imóveis & $4 \%$ & $4,0 \%$ & $4,0 \%$ & $2,0 \%$ & & & \\
\hline Máquinas e Equipamentos & $10 \%$ & $10,0 \%$ & $13,0 \%$ & $7,0 \%$ & & & \\
\hline Móveis e Utensílios & $10 \%$ & $10,0 \%$ & $10,0 \%$ & $10,0 \%$ & & & \\
\hline Equipam. Informática & $20 \%$ & $20,0 \%$ & $21,0 \%$ & $21,0 \%$ & & & \\
\hline Veículos & $20 \%$ & $20,0 \%$ & $18,0 \%$ & $18,0 \%$ & & & \\
\hline
\end{tabular}


Continuação ...

\begin{tabular}{|c|c|c|c|c|c|c|c|}
\hline \multirow[b]{2}{*}{ Bens do Imobilizado } & \multirow[b]{2}{*}{ Taxas Fiscais } & \multicolumn{3}{|c|}{ Empresa 15} & \multicolumn{3}{|c|}{ Empresa 16} \\
\hline & & 2008 & 2009 & 2010 & 2008 & 2009 & 2010 \\
\hline Edificações / Imóveis & $4 \%$ & $4,0 \%$ & $4,0 \%$ & $2,0 \%$ & $4,0 \%$ & $4,0 \%$ & $3,0 \%$ \\
\hline Máquinas e Equipamentos & $10 \%$ & $10,0 \%$ & $10,0 \%$ & $9,0 \%$ & $10 \%$ e $20 \%$ & $10 \%$ e $20 \%$ & $2,5 \%$ A $33 \%$ \\
\hline Móveis e Utensílios & $10 \%$ & $10,0 \%$ & $10,0 \%$ & $9,0 \%$ & $10,0 \%$ & $10,0 \%$ & $3 \%$ A $20 \%$ \\
\hline Equipam. Informática & $20 \%$ & $20,0 \%$ & $20,0 \%$ & $14,0 \%$ & $5,0 \%$ & $5,0 \%$ & $8 \%$ A $20 \%$ \\
\hline \multirow[t]{2}{*}{ Veículos } & $20 \%$ & $20,0 \%$ & $20,0 \%$ & $11,0 \%$ & $20,0 \%$ & $20,0 \%$ & $5 \%$ A $33 \%$ \\
\hline & & \multicolumn{3}{|c|}{ Empresa 17} & \multicolumn{3}{|c|}{ Empresa 18} \\
\hline Bens do Imobilizado & Taxas Fiscais & 2008 & 2009 & 2010 & 2008 & 2009 & 2010 \\
\hline Edificações / Imóveis & $4 \%$ & $0 \%$ a $4 \%$ & $0 \%$ a $4 \%$ & $2 \%$ a $3 \%$ & $3,6 \%$ & $3,6 \%$ & $3,4 \%$ \\
\hline Máquinas e Equipamentos & $10 \%$ & $10 \%$ a $30 \%$ & $10 \%$ a $30 \%$ & $5 \%$ a $20 \%$ & $9,6 \%$ & $9,6 \%$ & $9,1 \%$ \\
\hline Móveis e Utensílios & $10 \%$ & $10 \%$ a $30 \%$ & $10 \%$ a $30 \%$ & $7 \%$ a $10 \%$ & $10,1 \%$ & $10,1 \%$ & $13,3 \%$ \\
\hline Equipam. Informática & $20 \%$ & $20 \%$ a $30 \%$ & $20 \%$ a $30 \%$ & $20 \%$ a $50 \%$ & $19,8 \%$ & $19,8 \%$ & $20,0 \%$ \\
\hline \multirow[t]{2}{*}{ Veículos } & $20 \%$ & $20 \%$ a $30 \%$ & $20 \%$ a $30 \%$ & $10 \%$ a $18 \%$ & $16,4 \%$ & $16,4 \%$ & $10,5 \%$ \\
\hline & & \multicolumn{3}{|c|}{ Empresa 19} & \multicolumn{3}{|c|}{ Empresa 20} \\
\hline Bens do Imobilizado & Taxas Fiscais & 2008 & 2009 & 2010 & 2008 & 2009 & 2010 \\
\hline Edificações / Imóveis & $4 \%$ & $4,0 \%$ & $4,0 \%$ & $4,0 \%$ & & $4,0 \%$ & $4 \%$ a $5 \%$ \\
\hline Máquinas e Equipamentos & $10 \%$ & $10,0 \%$ & & & & $10,0 \%$ & $8 \%$ a $10 \%$ \\
\hline Móveis e Utensílios & $10 \%$ & $10,0 \%$ & & & & $10,0 \%$ & $10,0 \%$ \\
\hline Equipam. Informática & $20 \%$ & $20,0 \%$ & & & & $20,0 \%$ & \\
\hline \multirow[t]{2}{*}{ Veículos } & $20 \%$ & $20,0 \%$ & & & & $20,0 \%$ & $20 \%$ a $25 \%$ \\
\hline & & \multicolumn{3}{|c|}{ Empresa 21} & \multicolumn{3}{|c|}{ Empresa 22} \\
\hline Bens do Imobilizado & Taxas Fiscais & 2008 & 2009 & 2010 & 2008 & 2009 & 2010 \\
\hline Edificações / Imóveis & $4 \%$ & $4,0 \%$ & $4,0 \%$ & $2,5 \%$ a $4 \%$ & $4,0 \%$ & $2,2 \%$ & $5 \%$ a $8,3 \%$ \\
\hline Máquinas e Equipamentos & $10 \%$ & $10,0 \%$ & $10,0 \%$ & $6,67 \%$ a $12,5 \%$ & $10,0 \%$ & $8,8 \%$ & $2,2 \%$ a $50 \%$ \\
\hline Móveis e Utensílios & $10 \%$ & $10,0 \%$ & $10,0 \%$ & $10 \%$ a $20 \%$ & $10,0 \%$ & $8,2 \%$ & $2,9 \%$ a $50 \%$ \\
\hline Equipam. Informática & $20 \%$ & $20,0 \%$ & $20,0 \%$ & $10 \%$ a $20 \%$ & $20,0 \%$ & $21,4 \%$ & $8,3 \%$ a $100 \%$ \\
\hline \multirow[t]{2}{*}{ Veículos } & $20 \%$ & $20,0 \%$ & & $20 \%$ a $33,3 \%$ & $20,0 \%$ & $9,7 \%$ & $133138 \% \mathrm{a}$ \\
\hline & & \multicolumn{3}{|c|}{ Empresa 23} & \multicolumn{3}{|c|}{ Empresa 24} \\
\hline Bens do Imobilizado & Taxas Fiscais & 2008 & 2009 & 2010 & 2008 & 2009 & 2010 \\
\hline Edificações / Imóveis & $4 \%$ & $4,0 \%$ & $4,0 \%$ & $2,8 \%$ a $8,3 \%$ & $4,0 \%$ & $4,0 \%$ & $4,0 \%$ \\
\hline Máquinas e Equipamentos & $10 \%$ & $10,0 \%$ & $10,0 \%$ & $2 \%$ a $20 \%$ & $10 \%$ a $20 \%$ & $10 \%$ a $20 \%$ & $10 \%$ a $20 \%$ \\
\hline Móveis e Utensílios & $10 \%$ & $10,0 \%$ & $10,0 \%$ & $4 \%$ a $10 \%$ & $10,0 \%$ & $10,0 \%$ & $10,0 \%$ \\
\hline Equipam. Informática & $20 \%$ & $10,0 \%$ & $10,0 \%$ & $13 \%$ a $50 \%$ & & & \\
\hline \multirow[t]{2}{*}{ Veículos } & $20 \%$ & $20,0 \%$ & $20,0 \%$ & $11,1 \%$ a $33,3 \%$ & $20 \%$ a $40 \%$ & $20 \%$ a $40 \%$ & $20,0 \%$ \\
\hline & & \multicolumn{3}{|c|}{ Empresa 25} & \multicolumn{3}{|c|}{ Empresa 26} \\
\hline Bens do Imobilizado & Taxas Fiscais & 2008 & 2009 & 2010 & 2008 & 2009 & 2010 \\
\hline Edificações / Imóveis & $4 \%$ & $4,0 \%$ & $2,5 \%$ & $1,7 \%$ a $2,5 \%$ & $4,0 \%$ & $4,0 \%$ & $2,8 \%$ a $10 \%$ \\
\hline Máquinas e Equipamentos & $10 \%$ & $10,0 \%$ & $11,0 \%$ & $6,7 \%$ a $10 \%$ & $10,0 \%$ & $10,0 \%$ & $2,5 \%$ a $10 \%$ \\
\hline Móveis e Utensílios & $10 \%$ & $10,0 \%$ & $10,0 \%$ & $10 \%$ a $20 \%$ & $10,0 \%$ & $10,0 \%$ & $10,0 \%$ \\
\hline Equipam. Informática & $20 \%$ & $20,0 \%$ & $20,0 \%$ & $10 \%$ a $20 \%$ & & & $8,3 \%$ a $10 \%$ \\
\hline \multirow[t]{2}{*}{ Veículos } & $20 \%$ & $20,0 \%$ & $20,0 \%$ & $20,0 \%$ & $20,0 \%$ & $20,0 \%$ & $10 \%$ a $25 \%$ \\
\hline & & Empresa 27 & & & Empresa 28 & & \\
\hline Bens do Imobilizado & Taxas Fiscais & 2008 & 2009 & 2010 & 2008 & 2009 & 2010 \\
\hline Edificações / Imóveis & $4 \%$ & $4 \%$ a $6 \%$ & $2 \%$ a $4 \%$ & $2 \%$ a $4 \%$ & $4,0 \%$ & $2 \%$ a $4 \%$ & $1,7 \%$ a $2,5 \%$ \\
\hline Máquinas e Equipamentos & $10 \%$ & $3 \%$ a $8 \%$ & $4 \%$ a $6,5 \%$ & $4 \%$ a $13,8 \%$ & $10,0 \%$ & $7,5 \%$ a $20 \%$ & $\begin{array}{l}5,3 \% \text { a } \\
16,7 \%\end{array}$ \\
\hline Móveis e Utensílios & $10 \%$ & $5,0 \%$ & $6 \%$ a $10 \%$ & $6 \%$ a $10 \%$ & $10,0 \%$ & $10 \%$ a $29 \%$ & $5 \%$ a $10 \%$ \\
\hline Equipam. Informática & $20 \%$ & $10,0 \%$ & $15,0 \%$ & $15 \%$ a $16,8 \%$ & $20,0 \%$ & $2 \%$ a $44 \%$ & $12,5 \%$ a $25 \%$ \\
\hline Veículos & $20 \%$ & $20,0 \%$ & $20,0 \%$ & $18,5 \%$ a $20 \%$ & $21,0 \%$ & $8 \%$ a $37 \%$ & $\begin{array}{l}6,7 \% \text { a } \\
14,3 \%\end{array}$ \\
\hline
\end{tabular}




\section{Continuação ...}

\begin{tabular}{|c|c|c|c|c|c|c|c|}
\hline & & \multicolumn{3}{|c|}{ Empresa 29} & \multicolumn{3}{|c|}{ Empresa 30} \\
\hline Bens do Imobilizado & Taxas Fiscais & 2008 & 2009 & 2010 & 2008 & 2009 & 2010 \\
\hline Edificações / Imóveis & $4 \%$ & $4,0 \%$ & $4,0 \%$ & & $3,0 \%$ & $3,0 \%$ & $2,9 \%$ \\
\hline Máquinas e Equipamentos & $10 \%$ & $10,0 \%$ & $10,0 \%$ & & $6,6 \%$ & $7,3 \%$ & $6,7 \%$ \\
\hline Móveis e Utensílios & $10 \%$ & $10,0 \%$ & $10,0 \%$ & & $8,9 \%$ & $9,4 \%$ & $10,0 \%$ \\
\hline Equipam. Informática & $20 \%$ & $20,0 \%$ & $20,0 \%$ & & & & \\
\hline \multirow[t]{2}{*}{ Veículos } & $20 \%$ & $20,0 \%$ & $20,0 \%$ & & $10,0 \%$ & $9,8 \%$ & $20,0 \%$ \\
\hline & & \multicolumn{3}{|c|}{ Empresa 31} & \multicolumn{3}{|c|}{ Empresa 32} \\
\hline Bens do Imobilizado & Taxas Fiscais & 2008 & 2009 & 2010 & 2008 & 2009 & 2010 \\
\hline Edificações / Imóveis & $4 \%$ & $4,0 \%$ & $4,0 \%$ & $4 \%$ a $10 \%$ & $4 \%$ a $20 \%$ & $4 \%$ a $20 \%$ & \\
\hline Máquinas e Equipamentos & $10 \%$ & $5 \%$ a $10 \%$ & $5 \%$ a $10 \%$ & $4 \%$ a $20 \%$ & $10 \%$ a $20 \%$ & $10 \%$ a $20 \%$ & \\
\hline Móveis e Utensílios & $10 \%$ & $10,0 \%$ & $10,0 \%$ & $5 \%$ a $10 \%$ & $10 \%$ a $26,5 \%$ & $10 \%$ a $26,5 \%$ & \\
\hline Equipam. Informática & $20 \%$ & & & $10 \%$ a $20 \%$ & $20,0 \%$ & $20,0 \%$ & \\
\hline \multirow[t]{2}{*}{ Veículos } & $20 \%$ & $20,0 \%$ & $20,0 \%$ & $20 \%$ & $20,0 \%$ & $20,0 \%$ & \\
\hline & & \multicolumn{3}{|c|}{ Empresa 34} & \multicolumn{3}{|c|}{ Empresa 35} \\
\hline Bens do Imobilizado & Taxas Fiscais & 2008 & 2009 & 2010 & 2008 & 2009 & 2010 \\
\hline Edificações / Imóveis & $4 \%$ & $4,0 \%$ & $4,0 \%$ & $4,0 \%$ & & & \\
\hline Máquinas e Equipamentos & $10 \%$ & & & & $10,0 \%$ & $10,0 \%$ & $11,1 \%$ \\
\hline Móveis e Utensílios & $10 \%$ & $12,5 \%$ & $12,5 \%$ & $12,5 \%$ & $10,0 \%$ & $10,0 \%$ & $11,1 \%$ \\
\hline Equipam. Informática & $20 \%$ & $33,3 \%$ & $33,3 \%$ & $33,3 \%$ & $10,0 \%$ & $20,0 \%$ & $25,0 \%$ \\
\hline \multirow[t]{2}{*}{ Veículos } & $20 \%$ & & & & $20,0 \%$ & $20,0 \%$ & $16,7 \%$ \\
\hline & & \multicolumn{3}{|c|}{ Empresa 36} & \multicolumn{3}{|c|}{ Empresa 37} \\
\hline Bens do Imobilizado & Taxas Fiscais & 2008 & 2009 & 2010 & 2008 & 2009 & 2010 \\
\hline Edificações / Imóveis & $4 \%$ & $4,0 \%$ & $4,0 \%$ & $2 \% 10 \%$ & & $4,0 \%$ & $4,0 \%$ \\
\hline Máquinas e Equipamentos & $10 \%$ & $20,0 \%$ & $20,0 \%$ & $10,0 \%$ & & $10,0 \%$ & $10,0 \%$ \\
\hline Móveis e Utensílios & $10 \%$ & $10,0 \%$ & $10,0 \%$ & $10,0 \%$ & & & $10,0 \%$ \\
\hline Equipam. Informática & $20 \%$ & $20,0 \%$ & $20,0 \%$ & $10,0 \%$ & & & $20,0 \%$ \\
\hline \multirow[t]{2}{*}{ Veículos } & $20 \%$ & & & $10,0 \%$ & & & $20,0 \%$ \\
\hline & & \multicolumn{3}{|c|}{ Empresa 38} & & & \\
\hline Bens do Imobilizado & Taxas Fiscais & 2008 & 2009 & 2010 & & & \\
\hline Edificações / Imóveis & $4 \%$ & $4,0 \%$ & $4,0 \%$ & $4 \%$ & & & \\
\hline Máquinas e Equipamentos & $10 \%$ & $10 \%$ a $20 \%$ & $10 \%$ a $20 \%$ & $10 \%$ a $20 \%$ & & & \\
\hline Móveis e Utensílios & $10 \%$ & $10 \%$ a $20 \%$ & $10 \%$ a $20 \%$ & $10 \%$ a $20 \%$ & & & \\
\hline Equipam. Informática & $20 \%$ & $20,0 \%$ & $20,0 \%$ & $20 \%$ & & & \\
\hline Veículos & $20 \%$ & $20,0 \%$ & $20,0 \%$ & $20 \%$ & & & \\
\hline
\end{tabular}




\section{DADOS DOS AUTORES:}

\section{MAC DAVES DE MORAIS FREIRE}

Universidade Federal de Goiás, Faculdade de Administração, Ciências Contábeis e Ciências Econômicas - FACE.

Campus II - FACE

74001-970 - Goiania, GO - Brasil

\section{MICHELE RÍLANY RODRIGUES MACHADO}

Universidade Federal de Goiás, Faculdade de Administração, Ciências Contábeis e Ciências Econômicas - FACE.

Campus II - FACE

74001-970 - Goiania, GO - Brasil - Caixa-postal: 131

\section{LÚCIO SOUZA MACHADO}

Universidade Feredral de Goiás, Face - Faculdade de Administração, Ciências Contábeis e Ciências Econômicas.

Campus II (Samambaia)

74001-970 - Goiania, GO - Brasil - Caixa-postal: 131

\section{EMERSON SANTANA SOUZA}

Universidade Federal de Goiás, Face - Faculdade de Administração, Ciências Contábeis e Ciências Econômicas.

Campus II (Samambaia)

74001-970 - Goiania, GO - Brasil - Caixa-postal: 131

\section{JOHNNY JORGE DE OLIVEIRA}

Universidade Federal de Goiás, FACE - Faculdade de Administração, Ciências Contábeis e Ciências Econômicas.

Campus II (Samambaia)

74001-970 - Goiania, GO - Brasil - Caixa-postal: 131 